\title{
Absorption of chlorhexidine from the intact skin of newborn infants
}

\author{
JENNIFER COWEN, STUART H. ELLIS, AND JAMES MCAINSH
}

Department of Paediatrics and Neonatal Medicine, Hammersmith Hospital, London, and Imperial Chemical Industries Limited, Pharmaceuticals Division, Alderley Park, Macclesfield

SUMMARY 34 newborn infants who had been bathed in a standard manner with Hibiscrub* were studied to find out whether it was absorbed percutaneously. Low levels of chlorhexidine were found in the blood of all 10 babies sampled by heel prick, and 5 of 24 from whom venous blood was taken. The detection of chlorhexidine varied greatly with the method and timing of sampling, and no correlation was found between gestational or postnatal age and chlorhexidine levels.

Antiseptic substances have been applied to the skin and umbilical cord stumps of newborn babies for many years with a view to controlling bacterial colonisation and reducing the prevalence of neonatal infection (Farquarson et al., 1952; Williams and Oliver, 1969; Evans et al., 1970; Gezon et al., 1973; Dankert et al., 1977; Fares et al., 1977; Wald et al., 1977). Hexachlorophane, a phenolic derivative effective against Gram-positive organisms, has been the most widely used. This substance is now known to be absorbed through the intact skin, particularly in preterm infants (Curley et al., 1971; Powell et al., 1973; Tyrala et al., 1977). It has also been recovered from the brains of such babies, where it has been associated with a spongioform myelinopathy (Powell et al., 1973; Shuman et al., 1974, 1975). This has led to restriction in its use, particularly in infants of very low birthweights. Chlorhexidine, effective against Gram-positive and some Gram-negative bacteria (Lowbury et al., 1964, 1974), appeared to be an appropriate substitute. It is not absorbed in any significant amounts from the hands of adults, even after prolonged use (Case et al., 1976). As the skin of immature infants is known to be unusually permeable, this study was undertaken to determine the extent, if any, of chlorhexidine absorption.

${ }^{*}$ Hibiscrub is a detergent-based preparation containing $4 \%$ Hibitane chlorhexidine gluconate. Hibiscrub and Hibitane are trade marks, the property of Imperial Chemical Industries Limited.

Department of Child Health, Alder Hey Children's Hospital, Liverpool

JENNIFER COWEN, lecturer in child health

Pharmaceuticals Division, Imperial Chemical Industries Limited

STUART H. ELLIS, statistician

JAMES MCAINSH, biochemist

\section{Patients and methods}

34 infants nursed in the neonatal intensive care unit at Hammersmith Hospital between November 1974 and January 1977 were studied. The purpose and nature of the investigation was explained to their mothers, who agreed to their infants' inclusion; the study also had the sanction of the hospital's ethical committee.

All babies in the study were 'topped and tailed' using water alone until the umbilical cord separated. They were then (or when size and general condition permitted) bathed daily with Hibiscrub used in a standard way throughout. A small quantity of the substance was applied with the bather's hand to the baby's head, excluding the face, and washed off with plain water. Chlorhexidine was then applied to the rest of the body, excluding any areas of broken skin; the infant was next immersed up to his neck in a bath of plain water, and then dried.

Blood samples were taken by heel prick or from a vein on the back of the hand (see below). The sampling site was swabbed with $70 \%$ isopropyl alcohol, mopped dry with sterile cotton swabs, reswabbed with isopropyl alcohol and allowed to dry. Blood was taken at the same time as samples needed for clinical purposes if possible. The whole blood sample was stored at $4^{\circ} \mathrm{C}$ until spun. Serum after separation was also stored at $4^{\circ} \mathrm{C}$ until analysed by gas-liquid chromatography after solvent extraction, acid hydrolysis, diazotisation, and iodination. A straight line was fitted to each set of calibration data by the method of least squares. Estimates for the unknown concentrations, together with their $95 \%$ confidence limits, were made by direct calculation from this fitted line. All esti- 
mated concentrations which gave negative values, or whose $95 \%$ confidence limits included zero, were considered as being not statistically significantly different from values obtained from blank samples. The numerical values, however, are included for completeness.

The gestational ages of the infants were calculated using the mothers' last menstrual periods and checked by a neurological and morphological scoring method (Dubowitz et al., 1970). The 34 infants were divided into three groups.

Group 1 (10 infants). Blood samples were taken by heel prick at varying times after the first bath. Details of sexes, birthweights, gestational and postnatal ages are shown in Table 1 .

Group 2 (7 infants). Samples were taken by venepuncture 4 hours after the first bath in case any measurable chlorhexidine in group 1 infants merely reflected adsorption of chlorhexidine on to the skin. Clinical details are shown in Table 2.

Group 3 (17 infants). Venous samples were withdrawn 12 hours after bathing and at weekly intervals if possible. These infants were studied to see if accumulation occurred and to attempt to see whether there was any correlation between gestational and postnatal ages and chlorhexidine blood levels. Details are shown in Table 3.

\section{Results}

Chlorhexidine was found in samples of blood taken from all 10 preterm infants in group 1 (Table 1). It was not realised, at this stage, that chlorhexidine is so strongly adsorbed on to the skin surface that it was not removed by the alcohol wash, so these results were almost certainly due to contamination of the sample by residual chlorhexidine on the skin. Where the concentrations were estimated as being negative these are shown as zero in the table.

Unlike the heel prick results, those recorded in venous samples were near the limits of detection of the assay and, therefore, some of the positive values could have been due to chance. Those that are considered to be significantly different from zero, based on the $95 \%$ confidence limits, are marked with an asterisk in the Tables and will be referred to as being significant in the following remarks.

While venous samples from infants in group 2 appeared positive in 6 of the 7 babies (Table 2), the three 'significant' values in this group were recorded in the 3 babies of 36 weeks or less. The infant who had no detectable chlorhexidine (Case 16) had an identical twin (Case 15) in whom $63 \mathrm{ng} / \mathrm{ml}$ was reported but, as this result does not differ significantly from zero, the 2 may have behaved identically with respect to absorption. The concentration of 460 $\mathrm{ng} / \mathrm{ml}$ in Case 13 was very much higher than that in

Table 1 Clinical details and total chlorhexidine in group 1 infants (capillary blood taken 1 and 4 hours after 1st bath)

\begin{tabular}{|c|c|c|c|c|c|c|}
\hline \multirow[t]{2}{*}{ Case } & \multirow[t]{2}{*}{ Sex } & \multirow[t]{2}{*}{$\begin{array}{l}\text { Birthweight } \\
(g)\end{array}$} & \multirow[t]{2}{*}{$\begin{array}{l}\text { Gestational age at birth } \\
\text { (weeks) }\end{array}$} & \multirow[t]{2}{*}{$\begin{array}{l}\text { Age at 1st bath } \\
\text { (days) }\end{array}$} & \multicolumn{2}{|c|}{$\begin{array}{l}\text { Minimum chlorhexidine concentration } \\
(n g / m l)\end{array}$} \\
\hline & & & & & 1 hour & 4 hours \\
\hline 1 & $\mathbf{F}$ & 1140 & $28 \frac{1}{2}$ & 38 & $53^{*}$ & 31 \\
\hline 2 & F & 1680 & $32 \frac{1}{2}$ & 11 & $79^{*}$ & $184^{*}$ \\
\hline 3 & $\mathbf{F}$ & 1540 & 34 & 6 & $81^{*}$ & $134 *$ \\
\hline 4 & $\mathbf{M}$ & 1800 & 34 & 10 & $380^{*}$ & $439^{*}$ \\
\hline 5 & $\mathbf{M}$ & 2660 & 35 & 13 & $607^{*}$ & $1021^{*}$ \\
\hline 6 & $\mathbf{M}$ & 2330 & 36 & 11 & $404^{*}$ & $67^{*}$ \\
\hline 7 & $\mathbf{F}$ & 2240 & 36 & 5 & $260 *$ & 34 \\
\hline 8 & $\mathbf{F}$ & 2360 & 37 & 17 & $539^{*}$ & $333^{*}$ \\
\hline 9 & $\mathbf{M}$ & 2200 & $37 \frac{1}{2}$ & 9 & $75^{*}$ & \\
\hline 10 & $\mathbf{M}$ & 2440 & $37 \frac{1}{2}$ & 9 & $251 *$ & \\
\hline
\end{tabular}

*Denotes a result which is significantly different from zero.

Table 2 Clinical details and chlorhexidine concentration in group 2 infants (venous blood taken 4 hours after 1st bath)

\begin{tabular}{|c|c|c|c|c|c|}
\hline Case & Sex & $\begin{array}{l}\text { Birthweight } \\
(g)\end{array}$ & $\begin{array}{l}\text { Gestational age at birth } \\
\text { (weeks) }\end{array}$ & $\begin{array}{l}\text { Age at Ist bath } \\
\text { (days) }\end{array}$ & $\begin{array}{l}\text { Chlorhexidine concentration } \\
(n g / m l)\end{array}$ \\
\hline $\begin{array}{l}11 \\
12 \\
13 \\
14 \\
15 \dagger \\
16 \dagger \\
17\end{array}$ & $\begin{array}{l}\mathbf{F} \\
\mathbf{M} \\
\mathbf{M} \\
\mathbf{F} \\
\mathbf{M} \\
\mathbf{M} \\
\mathbf{F}\end{array}$ & $\begin{array}{r}700 \\
2030 \\
2440 \\
2180 \\
1940 \\
2320 \\
3020\end{array}$ & $\begin{array}{l}28 \\
33 \\
35 \\
35 \\
37 \\
37 \\
39\end{array}$ & $\begin{array}{r}84 \\
6 \\
7 \\
7 \\
4 \\
4 \\
8\end{array}$ & $\begin{array}{c}4 \\
101^{*} \\
460^{*} \\
169^{*} \\
63 \\
-56 \\
68\end{array}$ \\
\hline
\end{tabular}

*Denotes a result significantly different from zero. †Identical twins. 
Table 3 Chlorhexidine concentrations in group 3 infants (venous blood taken 12 hours after baths on days stated)

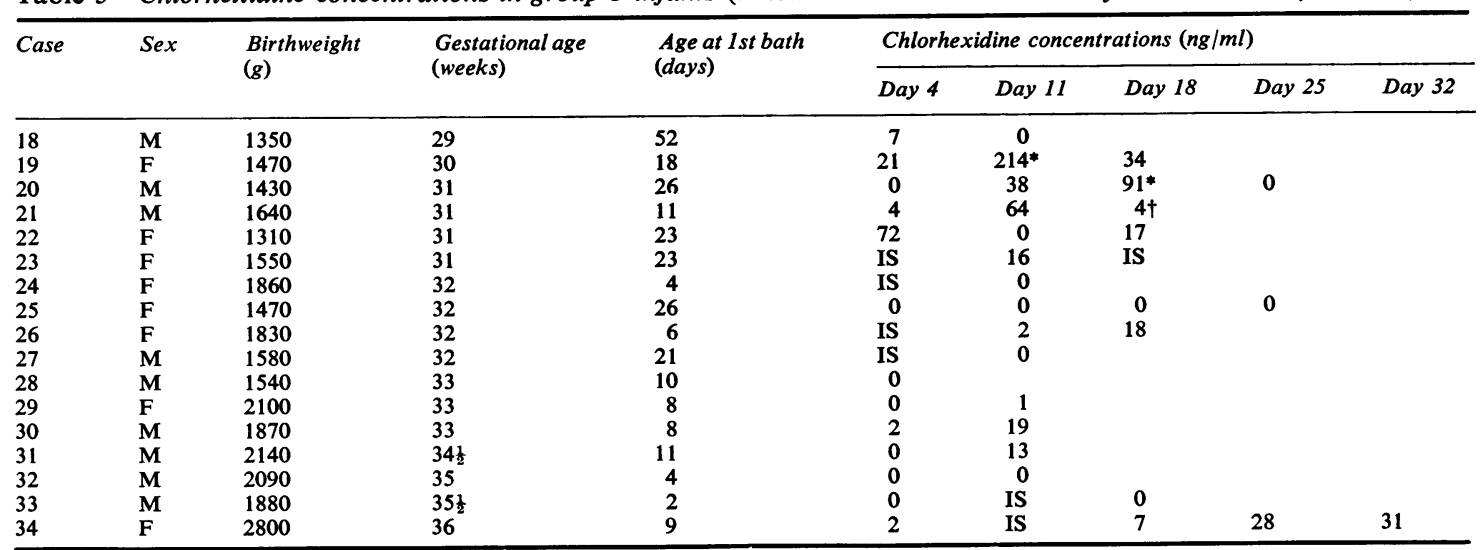

*Significantly different from zero based on the $95 \%$ confidence limits; tbaby not bathed in chlorhexidine for two days before this sample. IS = insufficient sample.

the others in the group for no obvious reason. Postnatal age did not appear to affect the results.

When the results from the 17 infants from group 3 were analysed, only 2 significant positives were found. The percentage of significant positives was thus reduced from $95 \%$ in group 1 , to $50 \%$ in group 2 , and $5 \%$ in group 3 . This would tend to confirm that at least some of the results in group 1 were owing to topical contamination with chlorhexidine. However, the only difference between group 2 (7 babies) and group 3 (17 babies) was that the samples were taken 4 hours after bathing in group 2 and 12 hours in group 3. It was not possible to detect any correlation between gestational-postnatal age and chlorhexidine levels in these groups, nor was there any tendency to accumulate the substance.

No unusual effects which could be attributed to chlorhexidine absorption were noted.

\section{Discussion}

This study was undertaken to ascertain whether chlorhexidine was absorbed through the intact skin of the newborn. It was prompted because hexachlorophane was in use as a bacteriostatic agent for more than 20 years before it was found to be absorbed (Curley et al., 1971), and to be associated with spongioform lesions in the brains of monkeys and preterm babies bathed in it (Hart, 1971, cited by Lockhart, 1972; Powell et al., 1973). The studies on hexachlorophane which led to these conclusions were undertaken when it was proposed to use hexachlorophane as a fungicide on fruit and vegetables.

The results reported from our survey show that chlorhexidine is detectable in the blood of some preterm and term infants after whole body bathing. Although there were more positive results in preterm babies, these were too few for statistical analysis. Percutaneous chlorhexidine absorption would not be surprising as many other substances are absorbed in this way, particularly in the neonatal period. These include hydrocortisone, trichlorocarbanilide, pentachlorophenol, and, of course, hexachlorophane (Fisch et al., 1963; Feinblatt et al., 1966; Armstrong et al., 1969; Robson et al., 1969). Nachman and Esterly (1971) demonstrated skin blanching with phenylephrine hydrochloride $10 \%$ in preterm but not term babies, thus confirming increased permeability in the immature. As any substance to which newborn skin is exposed may be absorbed to some extent it is a question of balancing its value against potential risks. There are differing views on the effectiveness of, or even the necessity for, topically applied antibacterial substances in newborn babies (Forfar et al., 1968; Evans et al., 1970; Gezon et al., 1973; Light and Sutherland, 1973; American Academy of Pediatrics Committee on Fetus and Newborn, 1974; British Medical Journal, 1977; Dankert et al., 1977), but it is beyond the scope of this paper to review opinions on this controversial subject.

There are no reports yet of any tissue toxicity due to chlorhexidine, but necropsy studies have not been made. Despite the extensive use of chlorhexidine in obstetrics, ear, nose, and throat surgery, in dentistry, and as a preoperative disinfectant, the only adverse reactions reported in adults have been associated with direct instillation into the middle ear, where in common with other antiseptics, it causes deafness. However, adults absorb virtually no chlorhexidine from the skin, even after prolonged use (Winrow $e t$ 
al., 1973). Newborn rhesus monkeys bathed daily with chlorhexidine digluconate showed no clinical evidence of toxicity (Case et al., 1976). Rats given chlorhexidine in their drinking water for 2 years showed no ill effects in life or at necropsy although there were easily detectable levels of chlorhexidine in the liver and kidney (Case et al., 1976). It has been shown to cause concentration-dependent precipitation of rat liver microsomal protein, probably due to RNA binding and possibly to membrane binding too; and it binds rat liver microsomes affecting various enzyme systems in them (Christensen and Jensen, 1974; Christensen et al., 1975). These effects were noted on subcellular fractions exposed directly to high concentrations of chlorhexidine, and all were thought to be related to the cationic amphipathic nature of chlorhexidine. Pharmacologically chlorhexidine is a biguanide, and the related substances phenformin and metoformin exert their metabolic effects by inhibiting fatty acid oxidation at toxic doses; they also inhibit oxidative phosphorylation (Muntoni, 1974).

With regard to the prime object of this study which was to demonstrate whether chlorhexidine is absorbed from the skin of newborn infants, the possibility of its adsorption to skin makes interpretation of results from heel prick samples inconclusive. When blood was obtained by venepuncture, however, small amounts of chlorhexidine were found in the blood of a few babies tested. Some of the most immature infants in this study were several weeks old when first bathed with chlorhexidine, so their skin permeability would already be less than at birth. Should further work be undertaken, sampling technique and postnatal age at exposure must be taken into account, and the use of chlorhexidine in obstetric units remembered.

We thank Mr B. F. Holmes, ICI, for analysis of chlorhexidine blood samples, Miss Castle and her staff of the premature baby unit, Hammersmith Hospital, for their help, and Dr Pamela Davies for encouragement.

\section{References}

American Academy of Pediatrics Committee on Fetus and Newborn. (1974). Skin care of newborns. Pediatrics, 54, 682-683.

Armstrong, R. W., Eichner, E. R., Klein, D. E., Barthel, W. F., Bennett, J. V., Jonsson, V., Bruce, H., and Loveless, L. E. (1969). Pentachlorophenol poisoning in a nursery for newborn infants. II. Epidemiologic and toxicologic studies. Journal of Pediatrics, 75, 317-325.

British Medical Journal (1977). Editorial: Hexachlorophane-yes or no? British Medical Journal, 1, 337-338.

Case, D. E., McAinsh, J., Rushton, A., and Winrow, M. J. (1976). Chlorhexidine: attempts to detect percutaneous absorption in man. In Chemotherapy, volume 3 , pp.
367-374. Edited by J. D. Williams and A. M. Geddes. Plenum: New York.

Christensen, F., and Jensen, J. E. (1974). The effect of chlorhexidine on some biochemical parameters of rat liver microsomes. Acta pharmacologica et toxicologica, 35, 33-41.

Christensen, F., Bleeg, H., and Jensen, J. E. (1975). The effect of chlorhexidine on some biochemical parameters of rat liver mitochondria. Acta pharmacologica et toxicologica, 36, 1-12.

Curley, A., Hawk, R. E., Kimbrough, R. K., Nathenson, G., and Finberg, L. (1971). Dermal absorption of hexachlorophane in infants. Lancet, 2, 296-297.

Dankert, J., Zijlstra, J. B., and Van Doorm, J. M. (1977). Bathing newborn infants in chlorhexidine digluconate (Hibiscrub). The effect on the bacterial flora in a maternity ward (in Dutch). Nederlandsch tijdschrift van geneeskunde, 121, 215-221.

Dubowitz, L. M. S., Dubowitz, V., and Goldberg, C. (1970). Clinical assessment of gestational age in the newborn infant. Journal of Pediatrics, 77, 1-10.

Evans, H. E., Akpata, S. O., and Baki, A. (1970). Factors influencing the establishment of the neonatal bacterial flora. II. The role of environmental factors. Archives of Environmental Health, 21, 643-648.

Fares, E., Selwyn, S., and Sethna, T. (1977). Chlorhexidine detergent and other alternatives to hexachlorophene for use in maternity nurseries (abstract). Journal of Clinical Pathology, 30, 785-786.

Farquarson, C. D., Penny, S. F., Edwards, H. E., and Barr, E. (1952). The control of staphylococcal skin infections in the nursery. Canadian Medical Association Journal, 67, 247-249.

Feinblatt, B. I., Aceto, T., Jr, Beckhorn, G., and Bruck, E. (1966). Percutaneous absorption of hydrocortisone in children. American Journal of Diseases of Children, 112, 218-224.

Fisch, R. O., Berglund, E. B., Bridge, A. G., Finley, P. R., Quie, P. G., and Raile, R. (1963). Methemoglobinemia in a hospital nursery. Journal of the American Medical Association, 185, 760-763.

Forfar, J. O., Gould, J. C., and MacCabe, A. F. (1968). Effect of hexachlorophane on incidence of staphylococcal and Gram-negative infection in the newborn. Lancet, 2, 177-180.

Gezon, H. M., Thompson, D. J., Rogers, K. D., Hatch, T. F., Rycheck, R. R., and Yee, R. B. (1973). Control of staphylococcal infections and disease in the newborn through the use of hexachlorophene bathing. Pediatrics, 51, 331-344.

Light, I. J., and Sutherland, J. M. (1973). What is the evidence that hexaclorophene is not effective? Pediatrics, 51, 345-354.

Lockhart, J. D. (1972). How toxic is hexachlorophene? Pediatrics, 50, 229-235.

Lowbury, E. J. L., Lilly, H. A., and Bull, J. P. (1964). Disinfection of hands: removal of transient organisms. British Medical Journal, 2, 230-233.

Lowbury, E. J. L., Lilly, H. A., and Ayliffe, G. A. J. (1974). Pre-operative disinfection of surgeons' hands. Use of alcoholic solution and effects of gloves on skin flora. British Medical Journal, 4, 369-372.

Muntoni, S. (1974). Inhibition of fatty acid oxidation by biguanides. Implications for metabolic physiopathology. Advances in Lipid Research, 12, 311-377.

Nachman, R. L., and Esterly, N. B. (1971). Increased skin permeability in preterm infants. Journal of Pediatrics, 79, 628-632. 
Powell, H., Swarner, O., Gluck, L., and Lampert, P. (1973). Hexachlorophene myelinopathy in premature infants. Journal of Pediatrics, 82, 976-981.

Robson, A. M., Kissane, J. M., Elvick, N. H., and Pundavela, L. (1969). Pentachlorophenol poisoning in a nursery for newborn infants. I. Clinical features and treatment. Journal of Pediatrics, 75, 309-316.

Shuman, R. M., Leech, R. W., and Alvord, E. C., Jr (1974). Neurotoxicity of hexachlorophene in the human. I. A clinicopathologic study of 248 children. Pediatrics, 54, 689-695.

Shuman, R. M., Leech, R. W., and Alvord, E. C., Jr (1975). Neurotoxicity of hexachlorophene in humans. II. A clinicopathologic study of 46 premature infants. Archives of Neurology, 32, 320-325.

Tyrala, E. T., Hillman, L. S., Hillman, R. E., and Dodson, W. E. 1977. Clinical pharmacology of hexachlorophene in newborn infants. Journal of Pediatrics, 91, 481-486.
Wald, E. R., Snyder, M. J., and Gutbelet, R. L. (1977). Group B $\beta$ hemolytic streptococcal colonization. American Journal of Diseases of Children, 131, 178-180.

Williams, C. P. S., and Oliver, T. K., Jr (1969). Nursery routines and staphylococcal colonization of the newborn. Pediatrics, 44, 640-646.

Winrow, M. J., Hedgecox, E., McDonald, R. S., and Siddall, J. (1973). Metabolic studies with ${ }^{14} \mathrm{C}$-chlorhexidine (Hibitane) in animals and man (abstract). Journal of Dental Research, 52, Supplement, 93.

Correspondence to Dr Jennifer Cowen, Alder Hey Children's Hospital, Eaton Road, Liverpool 12 2AP.

Received 5 October 1978

The following articles will appear in future issues of this journal:

Ring 20 chromosome in a child with seizures, minor anomalies, and retardation. J. M. Stewart, N. Cavanagh, and D. T. Hughes.

Acute intermittent porphyria and epilepsy. R. Biagini, R. Tignani, A. R. Fifi, and L. Nappini.

Comparative trial of manual and mechanical persussion technique with gravity-assisted bronchial drainage in patients with cystic fibrosis. M. Maxwell and A. Redmond.

Dubin-Johnson syndrome with some unusual features in a Chinese family. N. S. Lo, C.W. Chan, and J. H. Hutchinson.

Use of growth hormone gel. B. Lippe, S. D. Frasier, and S. A. Kaplan.

Changing incidence of neonatal hypermethioninaemia: implications for the detection of homocystinuria. P. D. Whiteman, B. E. Clayton, R. S. Ersser, P. Lilly, and J. W. T. Seakins. 